\title{
Current use of nucleoside analogues in the treatment of HIV infection
}

\author{
JULIO SG MONTANER MD FRCPC FCCP, CARLOS ZALA MD, LEILA SPOUR MD
}

\begin{abstract}
JSG Montaner, C ZALA, L SPOUR. Current use of nucleoside analogues in the treatment of HIV infection. Can J Infect Dis 1994;5(Suppl E):21E-26E. Nucleoside analogues continue to play a central role in the treatment of HIV infection. The recently published Concorde trial has been misinterpreted as demonstrating a lack of efficacy of zidovudine in the treatment of HIV disease. This is clearly not the case because zidovudine was prescribed to patients in both arms of the study. The Concorde study did confirm, however, the limitations of monotherapy in the treatment of this disease. Increased availability of other nucleoside analogues has allowed the development of newer therapeutic strategies. In this context, sequential use of zidovudine, followed by didanosine, has proved to be safe and effective in patients in varying stages of HIV disease. Preliminary results suggest that this strategy could be improved upon by using simultaneous combinations of zidovudine with didanosine or zalcitabine in full doses. The relative efficacy of these combinations remains to be established by phase III clinical trials, currently underway. Several new agents, including d4T, 3TC, nevirapine, other non-nucleoside reverse transcriptase inhibitors and the more recent protein inhibitors, are being tested either alone or in combination therapy regimens. It is anticipated that one or more of these agents will be clinically available soon. At present, the British Columbia Centre for Excellence in HIV/AIDS continues to recommend initiation of antiretroviral therapy with zidovudine in doses of $500 \mathrm{mg} /$ day for all HIV-infected individuals who are symptomatic (ie, who have AIDS or AIDS-related complex) and for those who are asymptomatic with a CD4 count consistently below $500 / \mathrm{mm}^{3}$. If the $\mathrm{CD} 4$ count is lower than $350 / \mathrm{mm}^{3}$, it is recommended that combination antiretroviral therapy be considered, namely zidovudine plus didanosine or zalcitabine in full doses. Obviously, the available evidence should be thoroughly discussed with eligible individuals to ensure that they have a full understanding of the potential benefits, adverse effects and limitations of currently available therapy.
\end{abstract}

Key Words: Didanosine, Human immunodeficiency virus, Zalcitabine, Zidovudine

\begin{abstract}
Usage actuel des analogues des nucléosides dans le traitement de l'infection au VIH
RÉSUMÉ : Les analogues des nucléosides continuent de jouer un rôle central dans le traitement de l'infection au VIH. L'essai Concorde, récemment publié, a interprété à tort comme inefficace la zidovudine dans le traitement de la maladie au viH. Cela n'est de toute évidence pas le cas, parce que la zidovudine a été prescrite aux patients des deux bras de l'étude. L'étude Concorde a effectivement confirmé toutefois ses limites en monothérapie dans le traitement de cette maladie. La venue d'autres analogues des nucléosides a permis la mise au point de nouvelles stratégies thérapeutiques. Dans ce contexte, l'emploi séquentiel d'analogues de la zidovudine, suivis de didanosine s'est révélé sûr et efficace chez des patients à divers stades de la maladie au viH. Les résultats préliminaires suggèrent que cette stratégie peut être améliorée par l'emploi simultané d'associations de zidovudine et de didanosine ou de zalcitabine en doses complètes. L'efficacité relative de ces traitements d'association reste à confirmer dans le cadre d'essais cliniques de phase III qui sont actuellement en cours. Divers nouveaux agents, y compris le d4T, le 3Tc, la névirapine et d'autres inhibiteurs de la transcriptase inverse non nucléosidique et les inhibiteurs de protéines plus
\end{abstract}

continued on next page

SPH-AIDS Research Program and Infectious Disease Clinic; British Columbia Centre for Excellence in HIV/AIDS; and Canadian HIV Trials Network, Vancouver, British Columbia

Correspondence and reprints: Dr JSG Montaner, St Paul's Hospital/University of British Columbia, 210 - 1033 Davie Street, Vancouver, British Columbia V6E 1M7. Telephone (604) 631-5036, Fax (604) 631-5210 


\begin{abstract}
récents, sont à l'essai soit seuls, soit en traitement d'association. L’on prévoit que l'un ou plus de ces agents sera disponible bientôt. À l'heure actuelle, le British Columbia Centre for Excellence in HIV/AIDS continue de recommander l'amorce d'un traitement antirétroviral par zidovudine en doses de $500 \mathrm{mg}$ par jour chez tous les sujets infectés au VIH qui sont symptomatiques (c'est-à-dire qui présentent un SIDA ou un complexe lié au SIDA) et chez ceux qui sont asymptomatiques, mais dont la numération des CD4 demeure sous les $500 / \mathrm{mm}^{3}$. Si la numération des cD4 est inférieure à $350 / \mathrm{mm}^{3}$, il est recommandé de recourir à un traitement antirétroviral d'association, notamment zidovudine plus didanosine ou zalcitabine en doses complètes. De toute évidence, les preuves disponibles doivent faire l'objet de discussions approfondies avec les candidats admissibles pour s'assurer qu'ils comprennent bien les avantages, les effets indésirables et les limites potentiels des traitements actuellement offerts.
\end{abstract}

$\mathrm{O}$ VER THE PAST COUPLE OF YEARS, AND WITH THE INcreased availability of effective anti-HIV compounds, a great deal of interest has emerged regarding the use of nucleoside analogues. A variety of therapeutic strategies has been explored in an attempt to maximize the efficacy and minimize the toxicity of these agents. Initially, the prevailing trend was to use sequential monotherapy as dictated by clinical events (toxicity or disease progression). Once the potential short term efficacy of the new nucleoside analogues was better understood, studies focused on combination schemes involving sequential administration of these agents at fixed intervals, independent of disease progression. More recently, studies have attempted to characterize the safety, pharmacokinetics and surrogate marker effect of simultaneously administered nucleoside analogues.

The following is a brief discussion of recently reported studies dealing with monotherapy and combination (sequential, alternating or simultaneous) nucleoside therapy strategies. Large clinical trials currently underway will provide the much needed answers regarding the definitive role of combination therapy in the management of HIV infection. Preliminary guidelines are offered for the effective use of combination therapy in HIV infection. It must be emphasized that these guidelines represent an interim measure adopted in the province of British Columbia to facilitate access to promising treatments pending the completion of definitive clinical trials.

The Concorde study: The recently published Concorde trial was originally designed in 1988 to determine whether symptom free HIV-infected individuals would benefit from starting zidovudine (AZT, Retrovir; Burroughs Wellcome) at randomization (immediate group) rather than deferring treatment until the onset of symptomatic disease (deferred group) (1). The efficacy endpoints of the study included clinical disease progression or death. In October 1989, following the termination of a similar study, the ACTG 019 in the United States, the protocol was modified to allow participants to begin zidovudine on the basis of the at least two $\mathrm{CD} 4$ counts of less than $500 / \mathrm{mm}^{3}$ at least one month apart (2). The recently published report describes the preliminary results from the intention to treat analysis of the Concorde study. Despite an early benefit in the immediate group, the results of this study failed to show any significant difference in benefit between immediate and deferred therapy in terms of survival or disease progression among symptom free individuals. Furthermore, the Concorde study also demonstrated a poor correlation between short term effect of zidovudine on CD4 count or disease progression and long term disease progression and survival, as had been suspected for some time (3).

The results of the Concorde study have been misinterpreted as demonstrating a lack of efficacy of zidovudine in the treatment of HIV disease. This is clearly not the case because zidovudine was prescribed to patients in both arms of the study. The Concorde study did demonstrate that in the context of zidovudine monotherapy there is no advantage, in terms of clinical progression or survival, whether this treatment is started immediately or in a deferred fashion. It must be emphasized, however, that study participants randomized to deferred therapy who had CD4 counts consistently below $500 / \mathrm{mm}^{3}$ were allowed to take zidovudine within this protocol. Of note, the recommendation for initiation of zidovudine therapy in the province of British Columbia is consistent with the criteria used in the deferred group of the Concorde study (as amended in October 1989).

The Concorde study compared two different strategies for the use of zidovudine monotherapy. The results of this study, therefore, offer no insight into the potential role of other therapeutic strategies. Recent data from controlled studies suggest that greater benefit can be derived by using either sequential treatment with zidovudine followed by didanosine or possibly using simultaneous combination of antiretroviral agents, as discussed below.

Sequential therapies: ACTG $116 \mathrm{~B} / 117$ is a recently published double-blind, comparative study of continuation zidovudine therapy versus change to didanosine following at least 16 weeks of zidovudine treatment (4). Patients were randomized to receive zidovudine 600 $\mathrm{mg} /$ day, didanosine at a dose of $500 \mathrm{mg} /$ day, or didanosine at a dose of $750 \mathrm{mg} /$ day (referred to as continuation zidovudine, didanosine, and high dose didanosine groups, respectively). The main eligibility criteria for this study included a prior diagnosis of AIDS or AIDS-related complex (ARC) and a CD4 lymphocyte count under $300 / \mathrm{mm}^{3}$, or asymptomatic disease with a CD4 lymphocyte count of less than $200 / \mathrm{mm}^{3}$. Primary end-points of the study were clinical events; time to 
occurrence of a new AIDS-defining opportunistic infection or death was recorded.

The study was terminated at the recommendation of the Safety Review Board in August 1991. A total of 913 patients was recruited between October 1989 and April 1991. Baseline characteristics were not significantly different between groups. Median CD4 lymphocyte count at entry was slightly under $100 / \mathrm{mm}^{3}$. Approximately $30 \%$ of patients had a diagnosis of AIDS, $60 \%$ a diagnosis of ARC, and 10\% were asymptomatic at entry. Prior median zidovudine exposure was close to one year.

For the didanosine, continuation zidovudine and high dose didanosine groups, respectively, totals of 94 , 125 and 115 clinical events (death or AIDS-defining illnesses) were diagnosed during the study, giving rise to one-year event rates of 34,48 and $41 \%$ in the three groups. The rate of clinical events for the didanosine group was lower $(\mathrm{P}=0.015)$ than for the continuation zidovudine group; the high dose didanosine and continuation zidovudine groups were not significantly different $(P=0.17)$ in this regard. A statistically significant difference in favour of didanosine therapy was found with regard to $\mathrm{CD} 4$ lymphocyte counts at weeks $2,8,12$, 16 and 24 . However, no significant difference in mortality among treatment groups was found.

Safety analysis at one year demonstrated that there were 17 episodes of pancreatitis in the didanosine group, six in the continuation zidovudine group and 31 in the high dose didanosine group. There were no differences among treatment groups with regard to the development of peripheral neuropathy. Hematological adverse effects were significantly more frequent in the continuation zidovudine group.

A similar study was recently completed in Canada among patients at earlier stages of HIV disease (5). This was a double-blind, comparative study of the efficacy and tolerability of didanosine versus continued zidovudine in HIV-infected persons with CD4 lymphocyte counts between 200 and $500 / \mathrm{mm}^{3}$ following at least six months of treatment with zidovudine at a dose not lower than $500 \mathrm{mg} /$ day.

Patients were randomized to zidovudine $(600$ mg/day) or didanosine (powder formulation; 334 or 500 $\mathrm{mg} /$ day for weights $60 \mathrm{~kg}$ or less, respectively) following at least six months of zidovudine at a dose of 500 $\mathrm{mg} /$ day or greater.

Of 232 participating patients, 60\% were asymptomatic, 30\% had ARC and 10\% had AIDS. Mean baseline CD4 lymphocyte counts were 328 and 334 cells $/ \mathrm{mm}^{3}$ for the didanosine $(n=113)$ and zidovudine $(n=119)$ groups, respectively. Change to didanosine led to a rapid and significant increase in baseline CD4 lymphocyte count persisting for at least 36 weeks. The CD4 lymphocyte count difference between the treatment groups was 47 and 90 cells $/ \mathrm{mm}^{3}$ at weeks $4 \quad(\mathrm{P}<0.001)$ and 24 $(\mathrm{P}<0.001)$, respectively, in favour of didanosine.
Within the latter study, viral sensitivity to zidovudine and didanosine was assessed in 102 (didanosine: 49 and zidovudine: 53) unselected patients. At entry, $21 \%$ and $28 \%$ of the didanosine and zidovudine groups were zidovudine-resistant (not significant). The probability of developing zidovudine resistance was 59\% at one year for the zidovudine-treated group; in contrast, no further zidovudine resistance developed during the study in the didanosine-treated group $(\mathrm{P}=0.01)$. Cross-resistance was documented in slightly fewer than $10 \%$ of patients in each group (not significant). No patient developed didanosine resistance during the study. Of note, a change to didanosine led to a decrease in the mean $50 \%$ inhibitory concentration ( $\mathrm{IC}_{50}$ ) for zidovudine among zidovudine-resistant patients, suggesting that zidovudine resistance is at least partially reversible.

The results of these studies demonstrate that a change to didanosine was more efficacious than continuing zidovudine in delaying time to the first AIDSdefining event or death among patients with advanced HIV disease. Change to didanosine led to a sustained increase in CD4 lymphocyte count, which was more prominent among patients with earlier-stage HIV disease. Early change to didanosine also prevented development of in vitro resistance to zidovudine, and often led to a decrease in $\mathrm{IC}_{50}$ among zidovudine-resistant patients. Of note, in vitro resistance to didanosine was extremely infrequent during the first year of didanosine therapy. Didanosine was safe and well tolerated when used at the currently recommended doses.

More recently, the results of ACGT $116 \mathrm{~A}$ have been released. This study involved 617 HIV-infected adults with AIDS or ARC and CD4 lymphocyte counts less than $300 / \mathrm{mm}^{3}$. Patients were randomized to zidovudine or didanosine at dosages similar to those described in ACTG 116B/117. Among 380 patients with no prior zidovudine experience, 18\% taking zidovudine developed a new AIDS-defining condition or died within one year (mortality rate 10\%), while 31\% and $29 \%$ of zidovudine-naive patients on high doses and usual doses of didanosine developed a similar outcome (mortality rate $9 \%$ and $4 \%$, respectively). Among the 118 patients with eight to 16 weeks of prior zidovudine use, $33 \%$ of zidovudine-treated patients versus $17 \%$ and $11 \%$ of high dose and usual dose didanosine-treated patients, respectively, developed a new AIDS-defining condition, or died within one year. Comparisons of zidovudine with didanosine-treated patients with eight or fewer weeks of prior zidovudine therapy were inconclusive. In this study, no statistical difference was found between the high and usual doses of didanosine, except that the former was associated with a higher risk of pancreatitis. As expected, zidovudine use was associated with a greater frequency of hematological toxicity compared with didanosine. No significant difference in rates of peripheral neuropathy was seen between zidovudine- and didanosine-treated patients. 
Preliminary results of a community-based, openlabel study comparing didanosine with zalcitabine in patients with very advanced disease who deteriorated on or became intolerant to zidovudine have recently been announced. This study, also known as CPCRA 020 , enrolled 467 patients, 66\% of whom had a prior diagnosis of AIDS. The median CD4 lymphocyte count was $37 / \mathrm{mm}^{3}$, and $63 \%$ of the patients were intolerant to zidovudine, induding $48 \%$ who developed hematological adverse effects. A new AIDS-defining event or death developed in $68 \%$ and $63 \%$ of didanosine- and zalcitabine-treated patients, respectively. Although there were slightly fewer deaths among zalcitabine-treated patients, this difference failed to reach statistical significance. A statistically greater increase in CD4 lymphocyte count was observed in didanosine-treated patients; however, CD4 lymphocyte counts declined between months 2 and 18 in both groups.

In summary, recently reported studies involving sequential monotherapy indicate that a change to didanosine following a limited period of zidovudine therapy can lead to a greater clinical benefit than monotherapy with zidovudine. As discussed in the following section, however, current practice has rapidly evolved away from sequential monotherapy to embrace simultaneous combination therapy with zidovudine and didanosine or zidovudine and zalcitabine.

For patients who cannot tolerate zidovudine, didanosine monotherapy remains a useful option. Whether zalcitabine has similar value to didanosine in these patients remains controversial, despite the results of CPCRA 020, since this study was limited to patients with very advanced disease (median CD4 lymphocyte count $37 / \mathrm{mm}^{3}$ ).

Combination therapy with zidovudine and zalcitabine: A study involving simultaneous administration of zidovudine and zalcitabine was recently published by Meng et al (6). In brief, the objective of this small phase I/II study was to assess the safety, immunological and antiviral effects of this combination. This was an openlabel, dose-ranging study. It involved 56 patients in six dose regimens. Patients had ARC or AIDS, a CD4 lymphocyte count less than $200 / \mathrm{mm}^{3}$, and no prior history of antiretroviral therapy. Eight to 11 patients were enrolled at each dose level studied. Dose levels (all by mouth) included zidovudine $100 \mathrm{mg}$ tid plus zalcitabine $0.005 \mathrm{mg} / \mathrm{kg}$ tid; zidovudine $200 \mathrm{mg}$ tid plus zalcitabine $0.005 \mathrm{mg} / \mathrm{kg}$ tid; zidovudine $300 \mathrm{mg}$ tid plus zalcitabine $0.005 \mathrm{mg} / \mathrm{kg}$ tid; zidovudine $100 \mathrm{mg}$ tid plus zalcitabine $0.01 \mathrm{mg} / \mathrm{kg}$ tid; zidovudine $200 \mathrm{mg}$ tid plus zalcitabine $0.01 \mathrm{mg} / \mathrm{kg}$ tid; and zidovudine $50 \mathrm{mg}$ tid without zalcitabine.

There were no differences among regimens with regard to zidovudine or zalcitabine pharmacokinetics. CD4 lymphocyte counts changed in a positive fashion in all combination schemes. The zidovudine $150 \mathrm{mg} / \mathrm{day}$ monotherapy arm had the smallest increase in CD4 lymphocyte count. Moreover, this group showed a steady decrease in CD4 lymphocyte counts after eight weeks into the study. All regimens had significant beneficial effects with regard to p-24 antigenemia and body weight changes. The best response was observed with $200 \mathrm{mg}$ of zidovudine tid plus zalcitabine at a dose of $0.01 \mathrm{mg} / \mathrm{kg}$ tid.

Combination therapy with zidovudine and zalcitabine led to a greater CD4 lymphocyte count increase. followed by a slower rate of $\mathrm{CD} 4$ lymphocyte count decline and longer suppression of p-24 antigenemia than with zidovudine monotherapy. Since patients in the zidovudine monotherapy arm of the study received a subtherapeutic dose of this agent, a retrospective analysis comparing zidovudine plus zalcitabine with zidovudine alone from the earlier ACTG 002 study was conducted. In this analysis a CD4 lymphocyte count response (defined by an increase of at least 50 cells $/ \mathrm{mm}^{3}$ twice, one month apart) was seen in $28 \%$ of the patients treated with conventional doses of zidovudine monotherapy, compared with $69 \%$ of the patients treated with zidovudine plus zalcitabine.

The authors concluded, therefore, that $200 \mathrm{mg}$ of zidovudine tid plus zalcitabine at a dose of $0.01 \mathrm{mg} / \mathrm{kg}$ tid should be recommended for future trials. On the basis of these results the United States Food and Drug Administration and the Health Protection Branch in Canada have approved zalcitabine for use in combination with zidovudine in symptomatic individuals with CD4 lymphocyte counts under $300 / \mathrm{mm}^{3}$ or asymptomatic individuals with CD4 lymphocyte counts under $200 / \mathrm{mm}^{3}$. Combination therapy with zidovudine and didanosine: A study involving zidovudine plus didanosine in combination was recently reported by Collier et al (7). This study was designed to determine the safety, pharmacokinetics, clinical effects, and antiviral effects of concurrent zidovudine and didanosine compared with zidovudine alone. This open-label, partially randomized phase I study enrolled 69 subjects divided into six groups treated with five different combinations of zidovudine/didanosine (at doses of 150/90, 300/334, $600 / 334,300 / 500$ and 600/500 mg/day, respectively) and a monotherapy group treated with zidovudine alone (600 mg/day). HIV-infected individuals with CD4 lymphocyte counts below $400 / \mathrm{mm}^{3}$ and who had a prior exposure to zidovudine of less than four months were eligible for the study. The effect of treatment on viral load was monitored using the polymerase chain reaction.

Baseline mean CD4 lymphocyte count was $259 / \mathrm{mm}^{3}$; 30 subjects had no previous antiretroviral therapy, and 31 had a mean prior zidovudine exposure of 65 days. All treatment schemes were well tolerated. Only three patients discontinued therapy, and six required dose modification for drug-related toxicity. No differences in rates of toxicity with combination therapy versus monotherapy were found. The median increase in the CD4 lymphocyte count was $166 / \mathrm{mm}^{3}$ for the zidovudine/ 
didanosine patients, compared with $77 / \mathrm{mm}^{3}$ for the zidovudine-alone group. CD4 lymphocyte counts increased by more than 50 cells on two consecutive counts in $72 \%$ of zidovudine/didanosine subjects versus $33 \%$ of zidovudine-alone subjects completing six months of therapy $(\mathrm{P}=0.036)$, with no significant difference in response rates among the five different combination therapy groups. CD4 lymphocyte counts remained above baseline values after 24 weeks of therapy in $63 \%$ of zidovudine/didanosine versus $25 \%$, of zidovudine-alone subjects $(\mathrm{P}<0.05)$. Plasma HIV RNA decreased significantly more often among zidovudine/ didanosine-treated subjects.

Similar results were reported by Ragni et al (8) from a four-arm study including varying combinations of zidovudine/didanosine therapy and didanosine monotherapy among asymptomatic HIV-infected patients with CD4 lymphocyte counts between 200 and $500 / \mathrm{mm}^{3}$. Eligible patients were stratified at entry according to CD4 lymphocyte counts and prior zidovudine exposure. Patients were randomized to four treatment arms, including low dose (zidovudine $100 \mathrm{mg}$ and didanosine $134 \mathrm{mg}$ daily), moderate dose (zidovudine 300 $\mathrm{mg}$ and didanosine $334 \mathrm{mg}$ daily), or high dose (zidovudine $600 \mathrm{mg}$ and didanosine $500 \mathrm{mg}$ daily) combination therapy, or didanosine alone (didanosine $500 \mathrm{mg}$ daily). At 24 weeks of follow-up all study regimens were well tolerated, with only one episode of neuropathy and no episodes of pancreatitis. Once again, combination therapy had a greater beneficial effect on CD4 lymphocyte counts than monotherapy.

From these studies we conclude that the zidovudine/didanosine combination is associated with a greater CD4 lymphocyte count increase than monotherapy with either zidovudine or didanosine. Additionally, zidovudine/didanosine led to a relatively large decrease in plasma viremia, a steady decrease in $\beta 2$ microglobulin, and increases in hemoglobin and body weight. Simultaneous admministration of zidovudine and didanosine was well tolerated, with no negative pharmacokinetic interaction.

Combination versus alternating therapy: Results of an ongoing study comparing zidovudine $300 \mathrm{mg} /$ day plus didanosine $250 \mathrm{mg} /$ day in combination versus zidovudine $600 \mathrm{mg}$ /day alternating at three-week intervals with didanosine $500 \mathrm{mg} /$ day were recently reported by Yarchoan et al (9). It should be emphasized that this study used half the usual dose of each agent in the simultaneous combination arm versus full doses of each agent in the alternating therapy arm.

Forty-one patients with AIDS or symptomatic HIV infection were studied. CD4 cell counts increased above baseline in both treatment groups. Mean CD4 cell count in the simultaneous regimen group was $108 / \mathrm{mm}^{3}$ above baseline. While patients on simultaneous therapy had a mean CD4 count above baseline at the end of the study (63 weeks), those on the alternating regimen fell below baseline following week 27 of the study. Patients on the simultaneous regimen were also reported to have significantly greater weight gain. Toxicities were felt to be generally mild and comparable between regimens. One patient died of pancreatitis and lactic acidosis in the simultaneous regimen arm. $\mathrm{Pa}-$ tients in both groups showed improvements in appetite, body weight and energy level. The results of this study suggest, therefore, that combination therapy with zidovudine and didanosine has greater therapeutic potential than alternating regimens.

\section{CURRENT STATUS OF NUCLEOSIDE COMBINATION THERAPY}

Combining nucleoside analogues remains a very attractive strategy against HIV. This is particularly true since the development of HIV strains resistant to nucleosides in vitro is likely to contribute to the clinical progression of HIV disease (10-13). Small clinical studies to date have suggested that zidovudine/didanosine or zidovudine/zalcitabine, given as simultaneous combinations, are generally well tolerated. Furthermore, on the basis of the effect of such combinations on surrogate markers, they provide preliminary evidence for enhanced efficacy. No statement can be made at this time regarding the relative safety, tolerability and efficacy of zidovudine/zalcitabine versus zidovudine/didanosine.

These data provide the necessary background to support the urgent need for expeditious completion of the appropriate clinical trials to establish definitively the role of combination therapy. At present, two large studies are underway comparing the clinical efficacy of combination therapy versus monotherapy: the Delta trial, a cooperative international study; and ACTG 118 in the United States.

At present, the British Columbia Centre for Excellence on HIV/AIDS continues to recommend initiation of antiretroviral therapy with zidovudine in doses of 500 mg per day for all HIV-infected individuals who are symptomatic (namely, who have AIDS or ARC) and for those who are asymptomatic with a CD4 count consistently below $500 / \mathrm{mm}^{3}$ (or a CD4 fraction consistently below 25\%). A change to didanosine after at least 16 weeks of zidovudine therapy may be considered because this has been shown to delay disease progression, decrease in $\mathrm{CD} 4$ count and development of viral resistance to zidovudine. If the $\mathrm{CD} 4$ count is lower than $350 / \mathrm{mm}^{3}$, combination antiretroviral therapy with zidovudine plus didanosine or zalcitabine in full doses should be considered. Obviously, the available evidence should be thoroughly discussed with eligible individuals to ensure that they have a full understanding of the potential benefits, adverse effects and limitations of available therapeutic strategies.

Because of the severity of illness it induces and the many unusual features presented by the HIV virus, HIV 
infection is the subject of continuous, intense study, resulting in numerous unexpected findings. Ensuring rapid and optimal clinical application of scientific findings is a continuing challenge for physicians in this field.

Currently, promising results with combination therapy are receiving attention. In a large number of studies, zidovudine, the first approved therapeutic agent for HIV infection, is being combined with a variety of chemically related and unrelated agents according to different dosing schedules and combinations.

It is important that clinical trials be vigorously pursued to provide definitive answers regarding the role of combination therapy in the management of HIV infection. Until results and conclusions are available from these studies, it is incumbent upon the medical community to facilitate access to clinical trials and, therefore, to promising treatments for HIV-infected patients.

\section{NOTE IN PRESS}

Developments in the field of antiretroviral therapy continue to evolve at a rapid pace. In the several months since this article was originally written, several new trials have been published or announced at scientific meetings. Of note, a number of studies has now confirmed a role for didanosine monotherapy in patients previously exposed to zidovudine, at varying stages of HIV disease. More importantly, evidence continues to accumulate supporting the safety and tolerability of

ACKNOWLEDGEMENTS: Dr Montaner is a National Health Research Scholar from the National Health Research and Development Program of Health Canada.

\section{REFERENCES}

1. Concorde Coordinating Committee. Concorde: MRC/ANRS randomised double-blind controlled trial of immediate and deferred zidovudine in symptom-free HIV infection. Lancet 1994;343:871-81.

2. Volberding PA, Lagakos SW, Koch MA, et al. Zidovudine in asymptomatic human immunodeficiency virus infection: a controlled trial in persons with fewer than 500 CD4-positive cells per cubic millimeter. N Engl J Med 1990;322:941-9.

3. Ruedy J, Schechter MT, Montaner JSG. Zidovudine for early human immunodeficiency virus (HIV) infection: Who, when and how? Ann Intern Med 1990;1 12:721-3.

4. Kahn JO, Lagakos SW, Richman DD, et al. A controlled trial comparing continued zidovudine with didanosine in HIV infection. N Eng J Med 1992;327:581-7.

5. Montaner JSG, Rachlis A, Gill J, et al. A double-blind study of ddI versus continued AZT among HIV+ individuals with CD4 counts 200 to $500 / \mathrm{mm}^{3}$ treated with AZT for at least six months. VIIIth International Conference on AIDS/IIIrd STD World Congress, 1992;MoB0081:Mo21. (Abst)

6. Meng Tze-Chiang, Fischl M. Boota A, et al. Combination therapy with zidovudine and dideoxycytidine in patients with advanced human immunodeficiency virus infection. A phase I/II study. Ann Intern Med 1992:116:13-20. simultaneous combination therapy involving $\mathrm{zi}-$ dovudine plus didanosine or zidovudine plus zalcitabine, in full doses. Despite the availability of preliminary results comparing zidovudine with didanosine or zalcitabine in simultaneous combination, this issue remains to be definitively addressed by the ongoing, large, phase III trials.

The field of antiretroviral therapy is expanding rapidly with the introduction of non-nucleoside reverse transcriptase inhibitors and other compounds, such as protein inhibitors, which are being tested in combination with nucleoside analogues. Two- and three-drug combinations are being aggressively pursued at different stages of the disease. Results of these studies are not likely to be available until some time in 1995 .

Two further agents are available for the management of HIV disease in patients who can no longer tolerate or benefit from the three approved anti-HIV drugs, namely zidovudine, didanosine and zalcitabine. These are d5T (stavudine) and 3TC (lamivudine). Approval of stavudine in doses of $40 \mathrm{mg}$ orally bid for the treatment of advanced HIV disease among patients who can no longer benefit from or tolerate other available therapies has been recommended to the United States Food and Drug Administration. The status of lamivudine as a monotherapy agent is less well defined. This drug continues to be studied aggressively in the context of combination therapy schemes.

7. Collier AC, Coombs RW, Fischl MA, et al. Combination therapy with zidovudine (ZDV) and didanosine (ddI) compared to ZDV alone in HIV-1 infection. Ann Intern Med 1993;1 19:786-93.

8. Ragni M, Dafni R, Amato DA, et al. Combination zidovudine and dideoxyinosine in asymptomatic HIV+ patients. VIIIth International Conference on AIDS/IIIrd STD World Congress, 1992;MoB0055:Mol5. (Abst)

9. Yarchoan R, Lietzau JA, Nguyen B, et al. A randomized pilot study of alternating or simultaneous zidovudine and didanosine therapy in patients with symptomatic human immunodeficiency virus infection. J Infect Dis 1994;169:9-17.

10. Larder BA, Darby G, Richman DD. HIV with reduced sensitivity to zidovudine isolated during prolonged therapy. Science 1989;243:1731-4.

11. Rooke R, Tremblay M, Soudeyns H, et al. (Canadian Zidovudine Multicentre Study Group): Isolation of drug-resistant variants of HIV-1 from patients on long-term zidovudine therapy. AIDS 1989;3:411-5.

12. Wainberg MA, Tremblay M, Rooke R, et al. Characterization of reverse transcriptase activity and susceptibility to other nucleosides of zidovudineresistant variants of $\mathrm{HIV}-1$ - Results from the Canadian Zidovudine Multicentre Study. Ann NY Acad Sci 1990;616:346-55.

13. Montaner JSG, Singer J, Schechter MT, et al. Clinical correlates of 'in vitro' HIV-1 resistance to zidovudine. Results of the Multicentre Canadian AZT Trial (MCAT). AIDS 1993;7:189-96. 


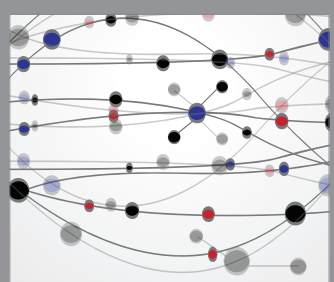

The Scientific World Journal
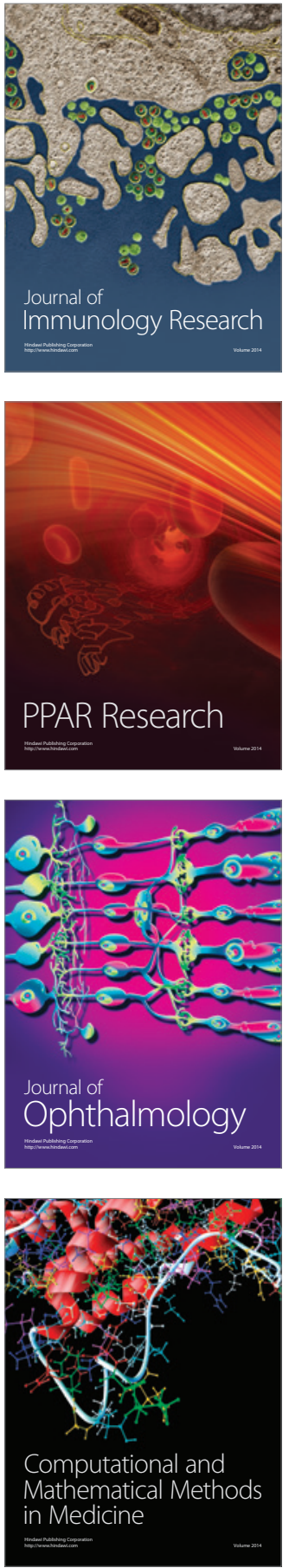

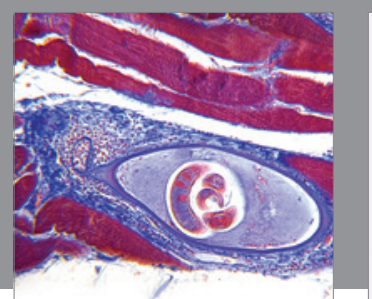

Gastroenterology Research and Practice

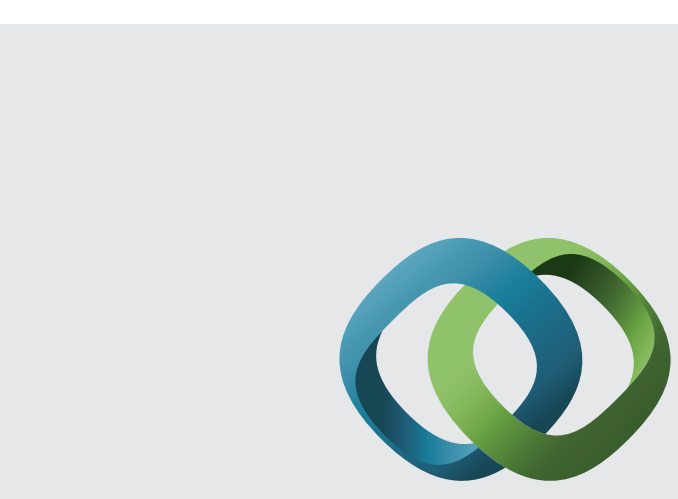

\section{Hindawi}

Submit your manuscripts at

http://www.hindawi.com
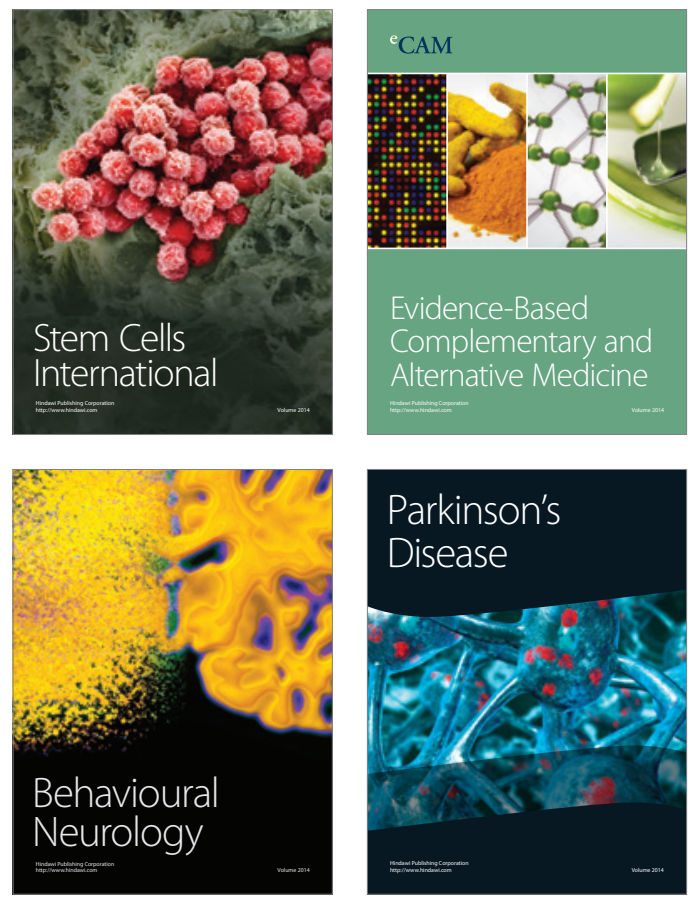
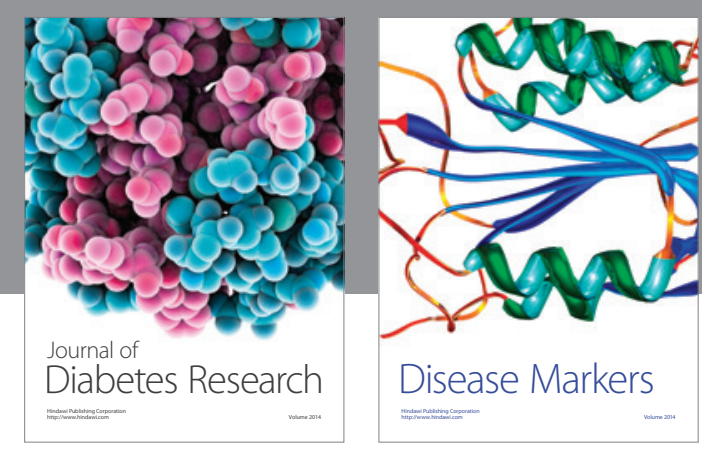

Disease Markers
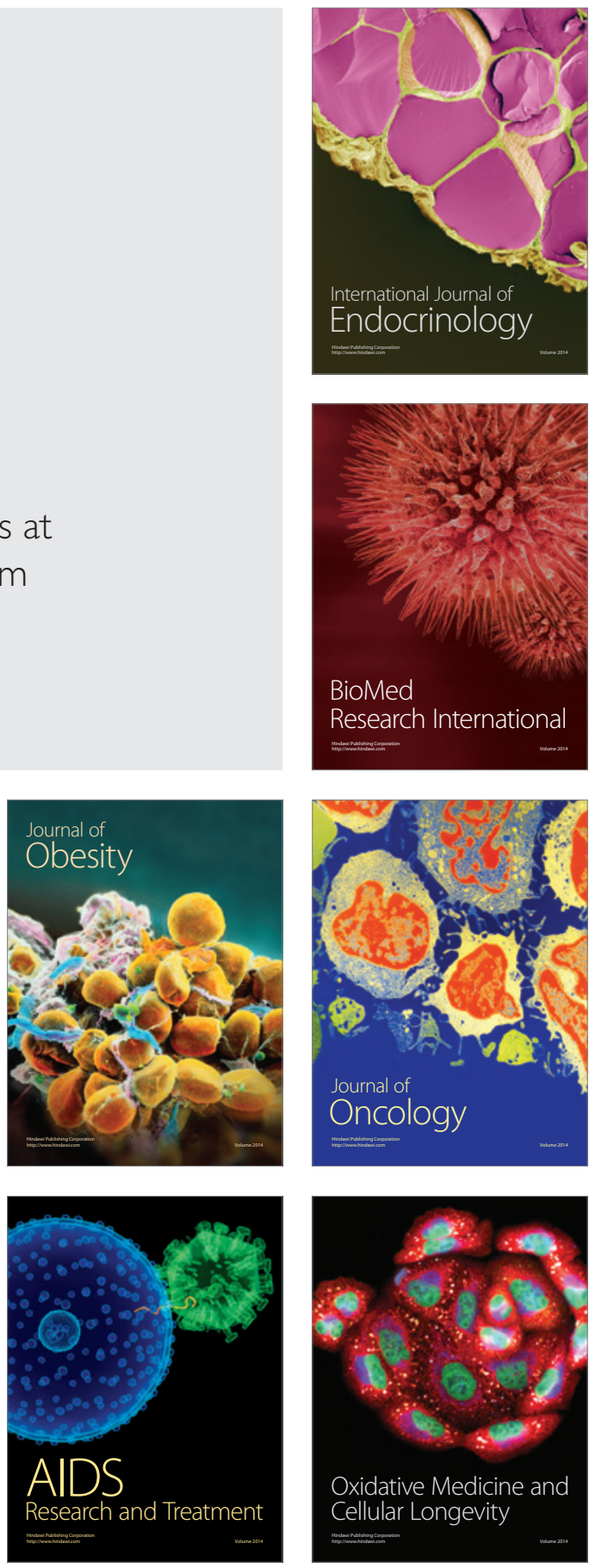